\title{
AUTOMATIC COMPACT DISC TRANSFER FOR QUALITY ASSURANCE TESTING
}

\author{
Ravi P. Ramachandran, John C. Chen, Linda M. Head, John L. Schmalzel and Hampton C. Gabler
}

\begin{abstract}
The purpose of this project was to design, build and test a low cost prototype that transfers compact discs (CDs) from a spindle to a computer based testing station. This will speed up the $C D$ production/testing interface and eliminate the need for manual operation. Along with a heavy product design technical component, the project included a real life educational experience for the four students who got credit for a one year advanced senior project. Various designs were considered and the optimal design (based on cost and performance) was prototyped.
\end{abstract}

Index Terms - automate, compact disc, product design, prototype, real life educational experience

\section{INTRODUCTION}

Rowan University's College of Engineering is committed to providing their students with significant laboratory and design experiences throughout their full four years as engineering students. In the Freshman year they are given an opportunity in the first semester to explore all four of the disciplines taught at Rowan (Electrical \& Computer, Civil \& Environmental, Mechanical, and Chemical) while learning about engineering measurement techniques [1][2]. Then that same year in the second semester the principles of design are introduced through the use of an experience in competitive assessment [3]. Small groups of students work on the investigation of a single product during the full semester. Along the way they are introduced to new analysis techniques and computer tools while learning in a "hands-on / minds-on" method the multidisciplinary nature of product design. By the sophomore year these students are ready for the next stage - actual design assignments in a well supervised but open environment. In the sophomore year the students are given a design assignment and, again in small (4-6 students) groups they all work on a single design project $[4][5]$. We maintain the multidisciplinary nature of the design process by not grouping the students by discipline, even though at this point they have chosen their majors and begun taking the introductory discipline-specific courses specified by their program. Also, written and oral communication are given much emphasis. At the junior and senior level, the students are ready to begin working on more real world design/research projects. The Automatic Compact Disc (CD) Transfer project was assigned to four junior/senior level students (two from Electrical and Computer Engineering and two from Mechanical
Engineering).. Four faculty members supervised the project which is described in this paper. Another example of a real world junior/senior level project is the design of a portable, low cost and rugged solar lantern [6].

\section{DESIGN PROBLEM AND OBJECTIVE}

The problem of automating a compact disc (CD) testing facility after $\mathrm{CD}$ production is an important problem to industries that mass manufacture compact discs [7][8]. It can be assumed that the $C D$ production process is automated in that newly manufactured CDs are placed on a spindle. The automation of $\mathrm{CD}$ testing avoids the need for a manual operator who would otherwise randomly selects several CDs and feed them to a testing system to verify their integrity. The system performs various inspection tests to determine if the CDs are satisfactory for recording and playing purposes and, if a problem or defect is found, the entire run of CDs is more thoroughly checked and the problem is rectified.

The project objective is to design, build and test a low cost prototype which transfers CDs from a spindle to a computer based testing station. This will speed up the CD production/testing interface and eliminate the need for manual operation. Along with a heavy product design technical component, the project included a real life educational experience for the four students who got credit for a one year advanced senior project. Various designs were considered and the optimal design (based on cost and performance) was prototyped.

\section{PRELIMINARY DESIGNS}

The students were first taken on an industrial field trip to observe $C D$ fabrication. For the prototype configuration, several design factors that the team considered were the placement on the fabrication line, price comparison, and software development. Using these design factors and observations, three separate preliminary designs were evaluated.

The first design consists of two "Pick and Place" arms. It requires two arms because a "Pick and Place" arm can only obtain two positions per travel and our project contains three separate positions. This design would be placed on the side of the replication line. It would pick the $\mathrm{CD}$ from the line at a stop position after the metallizer. The design would be housed on a cart with the $C D$ reader 180 degrees behind the first arm. The second arm would be 
placed perpendicular to the reader and retrieve the $\mathrm{CD}$ after inspection and place it onto a spindle (see Figure 1).

The second design has a Berger Lahr arm, which rotates about the Y-axis. The arm would be located at the end of the line and would place a newly manufactured $C D$ onto a spindle. The arm would then rotate past the spindle and place the $C D$ into the reader. When the $C D$ is finished inspection the arm needs to pick up the $\mathrm{CD}$ from the reader, place it on the spindle, and then go back to its home position to retrieve the next new $\mathrm{CD}$ (see Figure 2).

The third design also incorporates the Berger Lahr rotating arm. Only one arm is needed for this design because it can be programmed to move to approximately 16 different positions. The design includes the arm, reader, controller, and spindle. This apparatus would be placed along the side of the replication line (see Figure 3).

These designs were evaluated based on complexity, price, and availability. Design 1 was quickly eliminated due to its high cost and complexity. Even though Design 2 is the least expensive, it was not pursued since extensive reprogramming would make the task even more difficult. Therefore, the final design (Design 3) was chosen. Since it is a stand-alone system, it can be manufactured and tested it in a lab before incorporation onto an actual production line.

\section{Design 3 - THE ChOSEN DESIGN}

Figure 4 shows the electrical system of the prototype design. The controller is placed in the open. Therefore, a cover for the controller needs to be designed. This ensures that the operators' can't touch any open wires. A plexi-glass covering for the controller was used thereby preventing physical contact without hindering visual inspection. The plexi-glass was milled to the dimensions of the controller with rectangular pockets which allow it to fit evenly overtop. Finally small holes were drilled into the controller itself, and the covering was bolted on. This unique design not only ensures that the user cannot touch any open wires, it also gives the project a nice aesthetic look.

The next step is to incorporate the pneumatics into the system. A cylinder controls the disc pick-up head. The air source must be converted into a vacuum supply to pick up the compact disc. Therefore, there is the need to use an air system to get the head to move up and down and to pick up the disc. Figure 5 gives a diagram of the pneumatic system.

After designing the pneumatic system, a five-way valve is connected to the cylinder. When air is supplied to one end of the cylinder, a blow off is needed through the other end, otherwise the cylinder will never work. A coil is attached to the top of the valve so it can shift from one path to the other. A two-way valve is needed to act as a solenoid valve. This is connected in series with a venturi valve. The venturi valve transforms the airflow into a vacuum supply. The two-way valve acts as an on/off valve by turning the air supply on and off when entering the venturi. For the system, this valve is normally closed because the vacuum is only required for short periods. Finally, software is written in the Berger Lahr langauge to control movement of the arm. Figure 6 is a photograph of the final design.

\section{SUMMARY}

The aim of this project was in designing, building and testing a low cost prototype which transfers compact discs (CD) from a spindle to a computer based testing station. This project was extremely successful both as a real life design experience for the students and as a learning experience for the faculty who were involved in supervising a "start from scratch" product design. The initial project definition was not specific in terms of the technical specifications that were required. Rather, the charge to the design group was more general. We only had the final goal in mind, namely, to create an economical working prototype. This created the ideal situation for our students, they were faced with learning more about not only the technology but also about the context in which the technology is to be used. This is a lesson that we often do not have "time" to teach our students in the typical classroom situation. Rowan University's clinic program in engineering is the ideal place to explore not only traditional technical design but also a place where we can create for the students an opportunity to work on realistic engineering practice that we would all like our students to be aware of.

\section{LEARNING OUTCOMES}

The objectives of the junior/senior clinic course are:

1. Demonstrate expanded knowledge of the general practices and the profession of engineering through immersion in an engineering project environment of moderate to high complexity.

2. Demonstrate an ability to work effectively in a multidisciplinary team.

3. Demonstrate acquisition of new technology skills through use or development of appropriate computer hardware, software, and/or instrumentation.

4. Demonstrate effective use of project and personnel management techniques.

5. Demonstrate improved communication skills including written, oral, and multimedia. Conduct a patent search and write a patent disclosure for novel work.

The project described in this paper is an example of a one year junior/senior clinic experience. Table 1 gives the assessment results based on student feedback.

\section{REFERENCES}

1. R. P. Hesketh, K. Jahan, A. J. Marchese, C. S. Slater, J. L. Schmalzel, T. R. Chandrupatla and R. A. Dusseau, "Multidisciplinary Experimental Experiences in 
the Freshman Engineering Clinic at Rowan University", ASEE Annual Conference and Exposition, Session 2326, 1997.

2. K. Jahan, R. A. Dusseau, R. P. Hesketh, A. J. Marchese, R. P. Ramachandran, S. A. Mandayam and J. L. Schmalzel, "Engineering Measurements in the Freshman Engineering Clinic at Rowan University", ASEE Annual Conference and Exposition, Seattle, Washington, Session 1326, June 28--July 1, 1998.

3. R. P. Ramachandran, J. L. Schmalzel and S. A. Mandayam "Engineering Principles of an Electric Toothbrush", Proc. Conf. Amer. Soc. Eng. Edu., Session $2253,1999$.

4. J. A. Newell, A. J. Marchese, R. P. Ramachandran, B. Sukumaran and R. Harvey, "Multidisciplinary Design and Communication: A Pedagogical Vision", Internationa Journal of Engineering Education, Vol. 15, No. 5, pp. 376-$382,1999$.
5. R. P. Ramachandran, J. A. Newell, A. J. Marchese, B. Sukumaran, J. L. Schmalzel, H. Benavidez and J. Haynes, "A Pedagogical Concept of Integrating Multidisciplinary Design and Technical Communication", ASEE Annual Conference and Exhibition, St. Louis, Missouri, Session 2325, June 18--21, 2000.

6. L. M. Head, G. Canough and R. P. Ramachandran, "Design of a Robust and Low Cost Solar Lantern as a One Semester Project", ASEE Annual Conference and Exhibition, St. Louis, Missouri, Session 2793, June 18--21, 2000.

7. S. Miyaoka, "Manufacturing technology of the Compact Disc." In B. Blesser, B. Locanthi, and T. G. Stockham, Jr., editors, Collected Papers of the AES Premiere Conference - Digital Audio, New York: Audio Engineering Society, 1983.

8. K. Pohlmann, The Compact Disc Handbook, 1992.

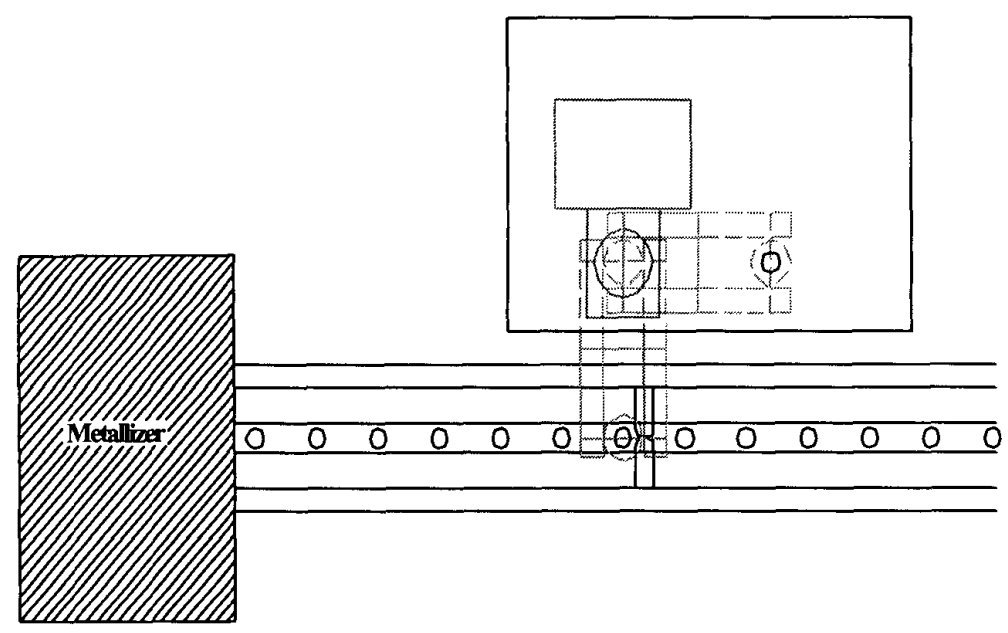

Figure 1: Design \#1 


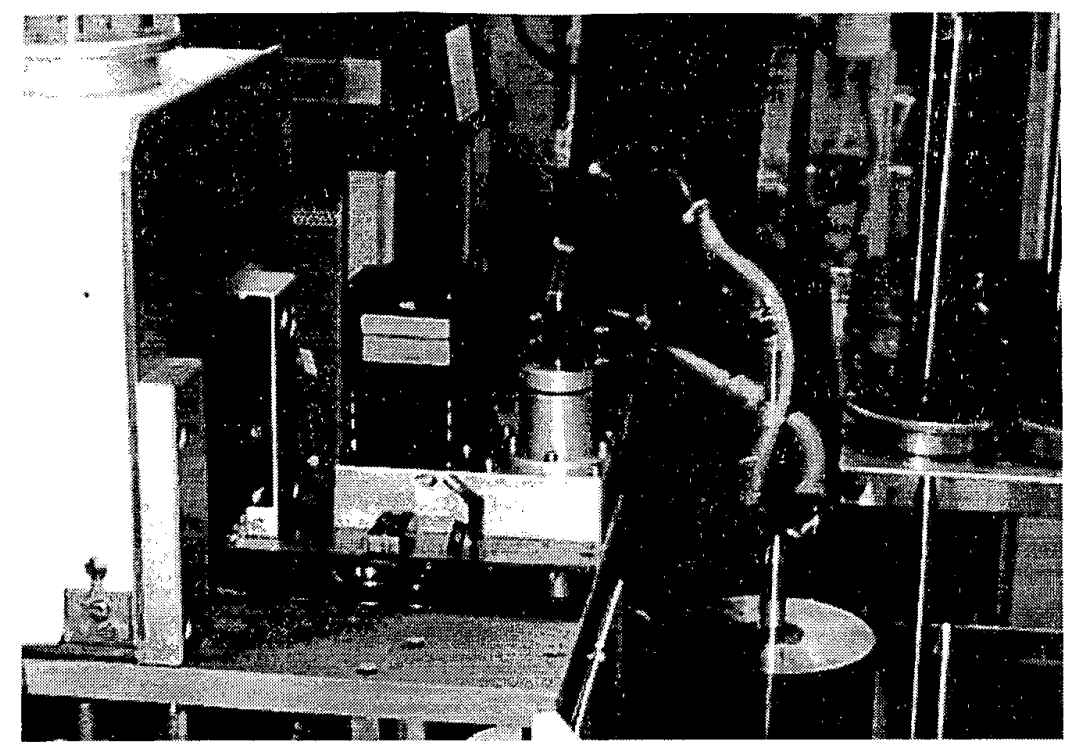

Figure 2: Design \#2

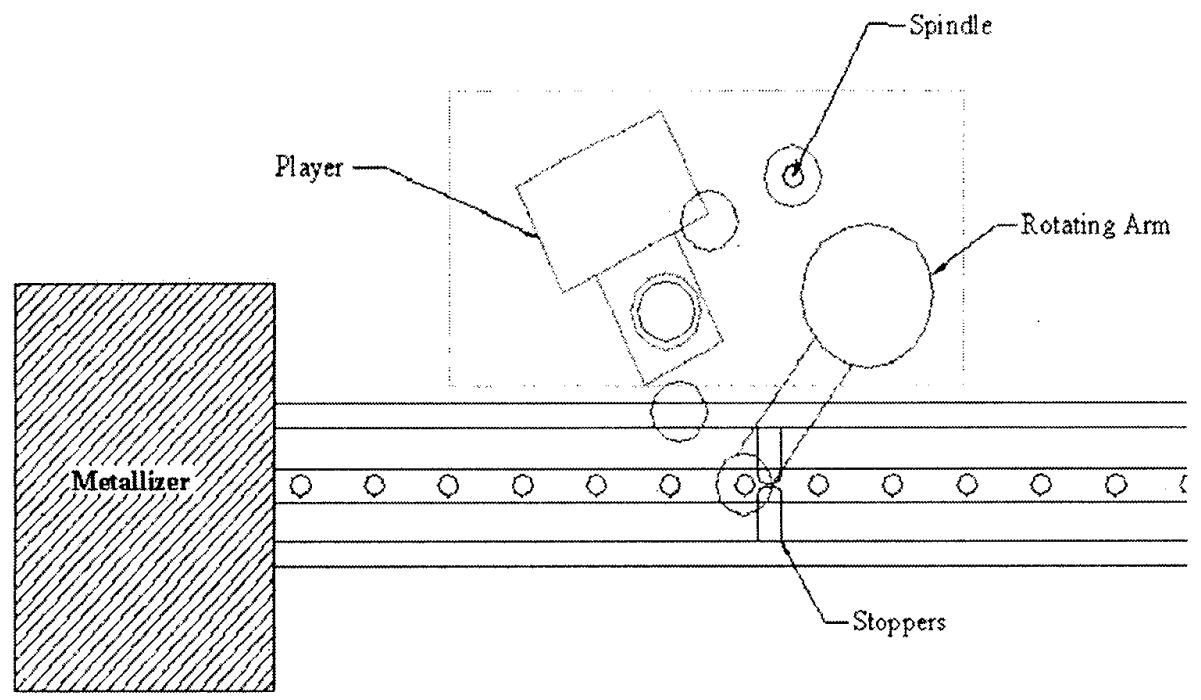

Figure 3: Design \#3 


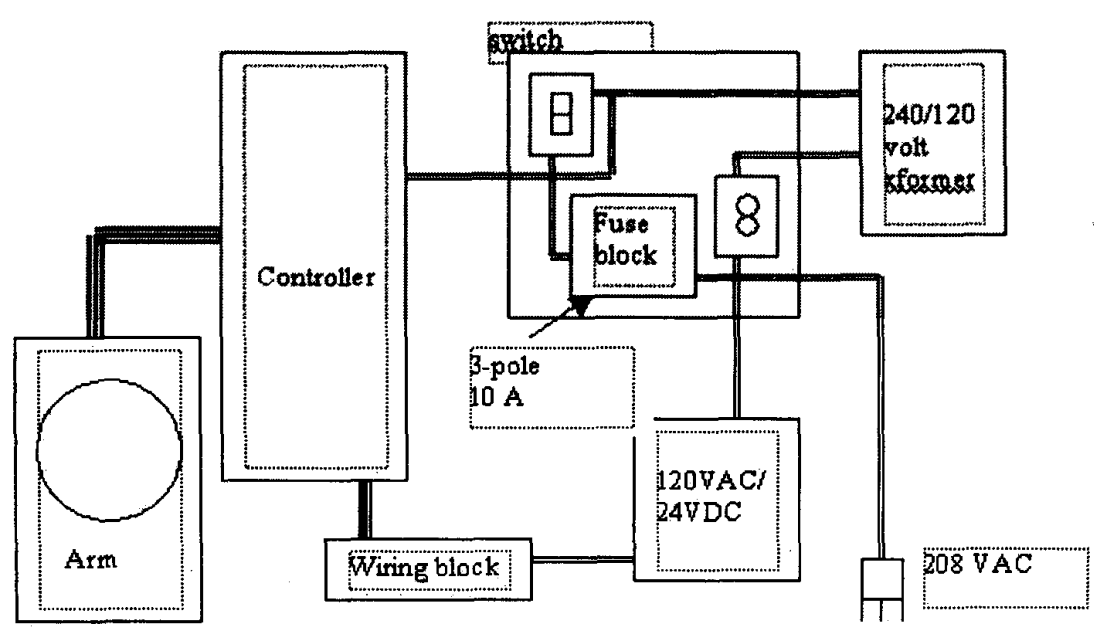

Figure 4: Design of Electrical System

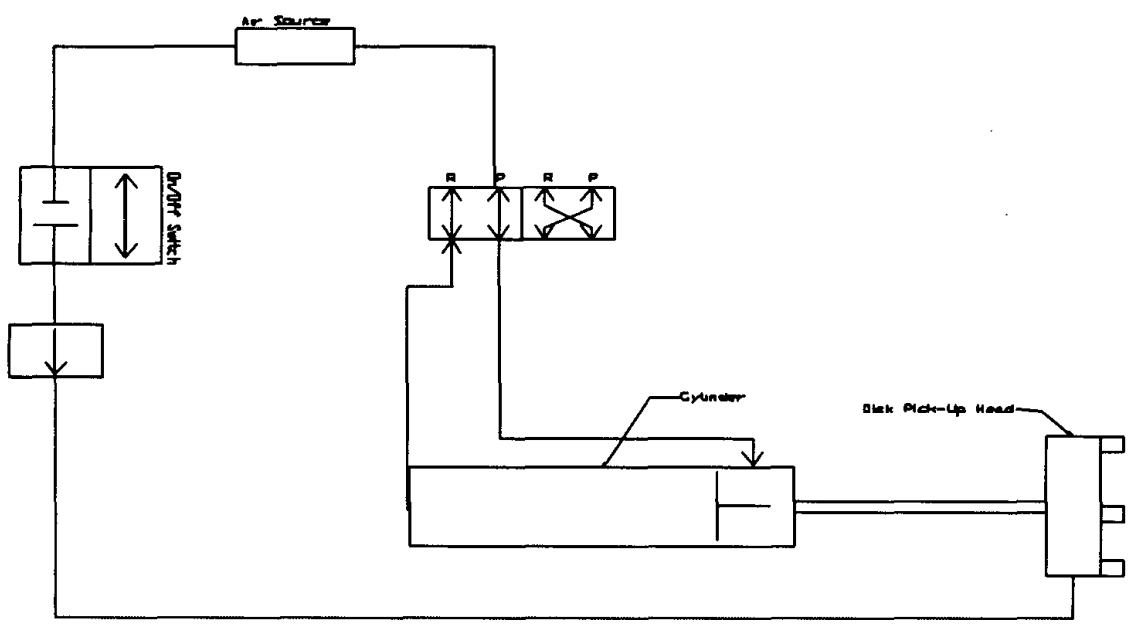

Figure 5: Design of Pneumatic System 


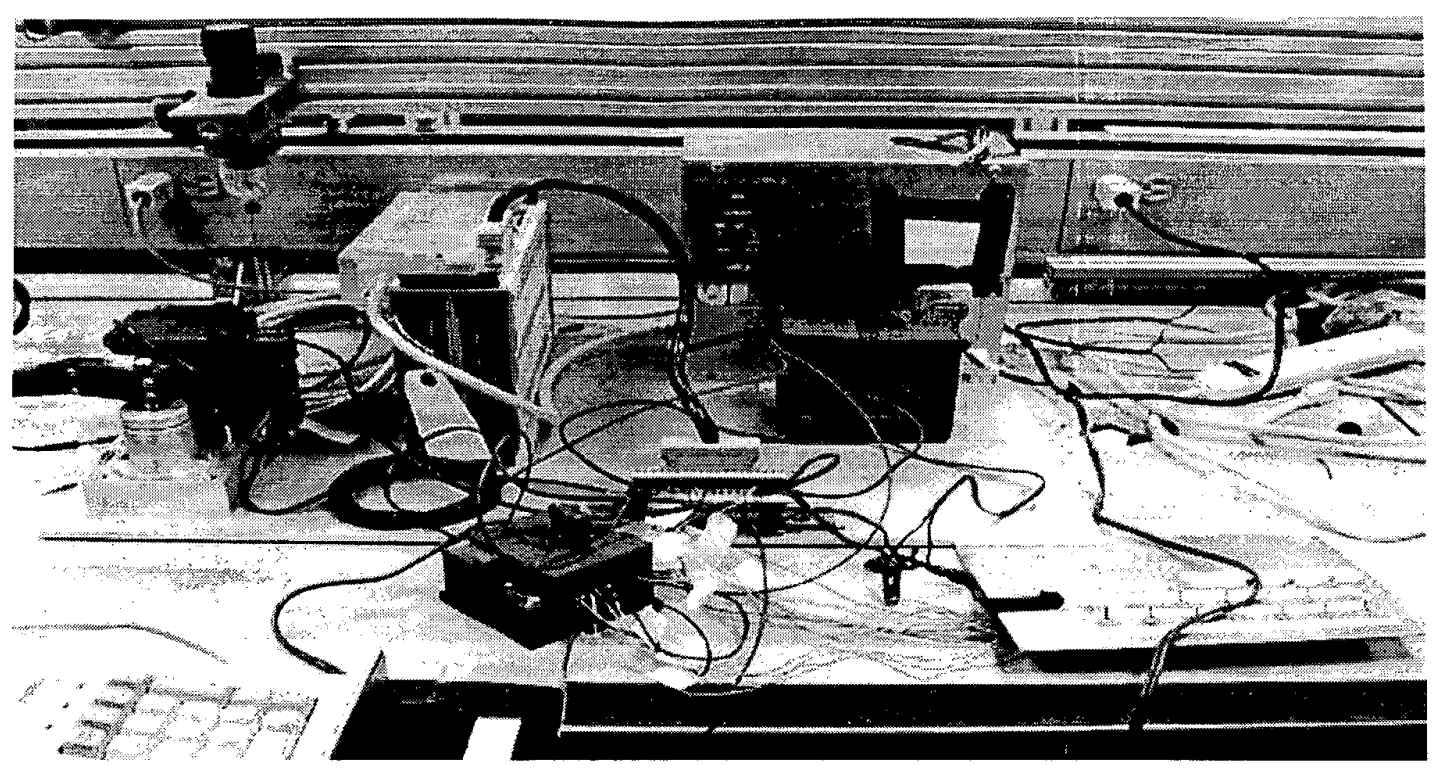

Figure 6. Final Project Design/Layout

\begin{tabular}{|l|c|c|}
\hline \multicolumn{1}{|c|}{ Question or Statement } & Mean & $\begin{array}{c}\text { Standard } \\
\text { Deviation }\end{array}$ \\
\hline Students self-rated ability on leadership and project management skills & 4.11 & 0.64 \\
\hline $\begin{array}{l}\text { Students self-rated ability on applying engineering theory and design } \\
\text { methodology }\end{array}$ & 3.91 & 0.86 \\
\hline Students self-rated ability on use of advanced engineering software & 3.00 & 1.30 \\
\hline $\begin{array}{l}\text { Students self-rated ability on using laboratory equipment and/or } \\
\text { fabrication and testing }\end{array}$ & 4.52 & 0.86 \\
\hline $\begin{array}{l}\text { Students self-rated ability on creative thinking and problem solving } \\
\text { needed for the project }\end{array}$ & 4.22 & 0.73 \\
\hline $\begin{array}{l}\text { Students opinion of whether their project could be the basis for a new } \\
\text { process or product }\end{array}$ & 3.80 & 1.07 \\
\hline Student assessment of the effectiveness of their team & 4.02 & 0.83 \\
\hline
\end{tabular}

Table 1. Assessment Results (1 - Poor, 2- Fair, 3 - Average, 4 - Above Average, 5 - Excellent) 